\title{
Increase in crop damage caused by wild boar (Sus scrofa L.): the "refuge effect"
}

\author{
Andrea Amici • Fioravante Serrani • \\ Carlo Maria Rossi • Riccardo Primi
}

Accepted: 8 September 2011 / Published online: 14 October 2011

(C) INRA - DIB / Springer-Verlag France 2011

\begin{abstract}
The occurrence of crop damage by wild boars raised dramatically in the last decades, implying an increase in social conflicts, expenditures for compensation and a risk to natural ecosystems. Many researchers have explained this phenomenon by considering wild boar biology, behaviour and abundance. Little or no attention has been devoted to wildlife management and the agricultural mosaic. We hypothesised that the agricultural structure of the landscape and wildlife management planning, including hunting, can play a relevant role in causing crop damage. We studied a Mediterranean area in central Italy that is characterised by a patchy agriculture, dividing the surface into hexagons. A large number of terrain parameters were calculated at the large (hexagons) and local (buffer) scale, including the topography, land use and agricultural management. We also considered wildlife variables such as the number of wild boar shot down, hunting management and the legal status of the wild boar. The terrain and management data for each hexagon were submitted to a generalised binomial stepwise multiple logistic regression. The resultant model demonstrated an accuracy of 0.76 , a misclassification rate of 0.24 and an odds ratio of 10.41 . The most important variables selected by the regression were the woods in the area where hunting was banned $(P<$ $0.001)$, a $1-\mathrm{km}$ buffer of intensively cultivated farmland close to the woods where hunting was banned $(P<0.001)$, a $1-\mathrm{km}$ buffer of intensively cultivated farmland along the river $(P<0.05)$, the forest edge $(P<0.001)$, and the mean
\end{abstract}

\footnotetext{
A. Amici $(\bowtie) \cdot$ F. Serrani - C. M. Rossi • R. Primi

Department of Agriculture, Forestry, Nature and Energy,

University of Tuscia,

Via S. Camillo de Lellis, snc,

01100 Viterbo, Italy

e-mail: amici@unitus.it
}

number of wild boar that were shot $(P<0.05)$. In this study, we proved that an important factor in explaining crop damage is the "refuge effect" (a buffer close to the wooded areas where hunting was banned) and the 1-km buffer along possible dispersion routes.

Keywords Sus scrofa . Wild boar. Crop damage . Regression · Ungulates · Wildlife management · Agricultural landscape

\section{Introduction}

The increase in conflicts between humans and wild ungulates has become particularly intense in recent decades. These clashes arise for different reasons, including the risk of disease transmission from the wild population to humans, livestock or other domestic animals, road collisions with vehicles, damage to forests and its regeneration (Groot-Bruinderinck et al. 1994), and damage to agricultural lands and pastures (Schley and Roper 2003). For wild boar (Fig. 1), their extensive rooting for the underground parts of plants and their predation on birds could pose a threat to the ecosystem (Giménez-Anaya et al. 2008), especially in parks, and in the Natura 2000 network of protected areas.

Although the problem of vehicle collision includes a risk for humans, from an economic point of view, the most significant problem related to wild boars is the damage to agricultural crops and grasslands, amounting to several million Euros every year. In Italy, wild boar (Sus scrofa L. 1758) are the most common wild ungulate in terms of population size (more than 600,000 units), and the population is expected to continue to grow in the coming decade. Wild boar have a distribution area covering approximately $64 \%$ of the Italian territory (Carnevali et al. 


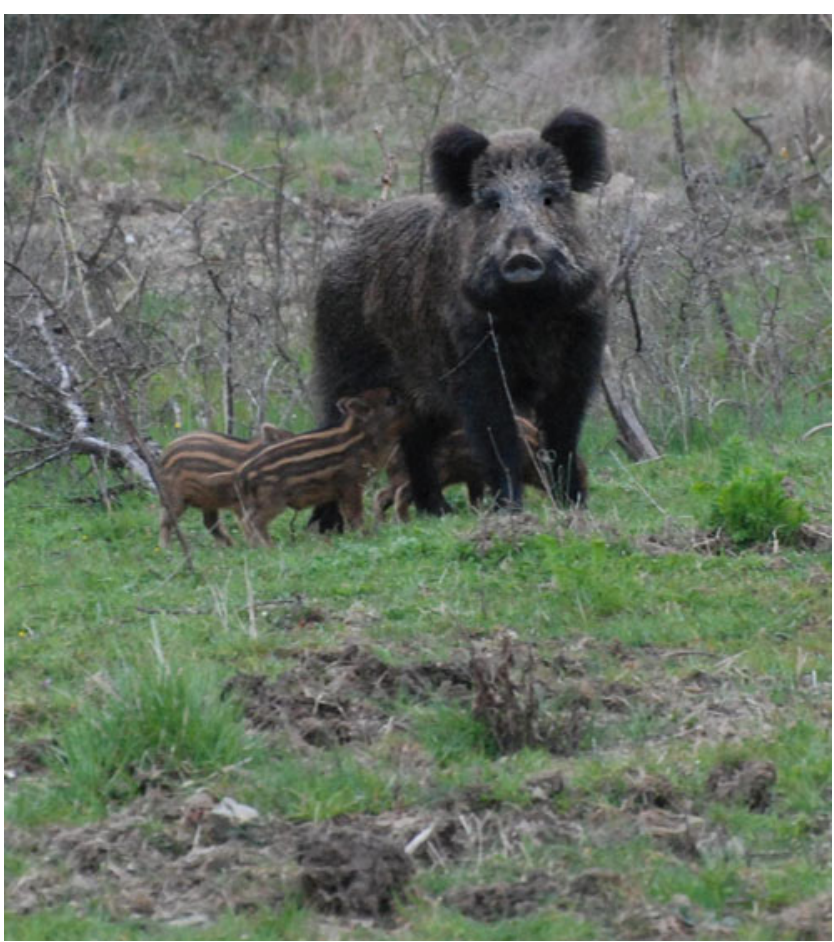

Fig. 1 A wild boar sow with piglets, rooting in the foreground

2009) and are responsible for the largest proportion of the crop damage.

Wild boar are considered an omnivorous species. Their nutritional requirements are satisfied predominantly by plant matter (90-99\% of ingestion), with a relatively poor supplement of animal matter (1-10\%), according to seasonal availability (Pinna et al. 2007). In the Mediterranean biomes, the most commonly ingested part is the underground portion of the plants, such as the roots and bulbs (ingested mainly after rooting activity), followed by the green parts and fruits (fleshy or Mediterranean scrub fruit). The lowest proportion of ingested food is animal matter in the form of earthworms, terrestrial arthropods and carcasses, insect larvae and birds (brooding or moulting) (Pinna et al. 2007). The consumption by wild boar of crops, such as maize, wheat, barley, rye, oats, rice, sorghum, potatoes, grasses and sugar beets, was very common throughout Europe and led to crop damage and consequently to economic losses and farmer irritation (Schley and Roper 2003).

Another feeding source is supplemental provisions provided by hunters to attract the wild boar to particular areas for hunting or to keep them away from the cultivated fields. The feed provided by hunters is usually a cereal (in most cases, maize). This feed increases the prolificacy of the boar and may distort their consumption of other foods, especially the roots and animal matter. Because the supplementary feed, such as maize, is rich in carbohydrates but low in protein, the excess energy it produces may be compensated by actively searching for protein sources, such as insect larvae and roots (GrootBruinderinck et al. 1994).

In the case of wild boar, several studies have suggested relationships between crop damage and environmentally related variables, such as the edge effect of the forest (Thurfjell et al. 2009), ditches, stone walls, rows of trees or bushes that are located close to fields $(<54 \mathrm{~m}$ from the forest), which increase the probability of damage. These results are often controversial, as are the variables, such as forest cover and landscape fragmentation, road or human population density (Schley et al. 2008). Other authors have suggested that some crops are susceptible to wild boar damage due to their stage of maturity and the extent of the crop area (Schley et al., 2008) or due to the overnight activity of this species (Keuling et al. 2009). Crop damage is positively related to an abundance of wild boars in the area (Schley et al. 2008) and negatively related to the hunting effort. Controversial results are reported for the relationship between crop damage and hunting bags (Geisser and Reyer 2004). In our opinion, an overlooked factor affecting population size is the legal status of the species (private or free hunting), and the widespread presence of ban hunting areas likely plays a role of "refuge areas".

The description of wild boar-related damage is associated with the analysis of a large number of variables, which contribute independently or jointly to the phenomenon and make it difficult to identify which are most significant. Logistic regression has been shown to be useful in building predictive models concerning biologically correlated events, starting from a set of categorical or continuously independent predictor variables (Real et al. 2006).

To expand upon these observations, a damage dataset, which was collected in a Mediterranean area in central Italy, was analysed, and the following points were considered: (1) the study of the main factors affecting crop damage by wild boar in a Mediterranean area in central Italy that is characterised by patchy agriculture; (2) the identification of agricultural and hunting management criteria and the legal status of the species as possible factors affecting crop damage by wild boar on a large scale; (3) the selection of possible predictors extrapolated from a GIS (Geographical Information System) dataset to identify the areas at risk for crop damage. This study aims to evaluate the effect of agricultural and hunting management criteria, such as bans on hunting in the wooded areas, as a "refuge effect" on the onset of crop damage.

\section{Materials and methods}

\subsection{Study area}

The study area is represented by the Viterbo Province (361,389 ha), located in the Lazio Region of central 
Italy $\left(42^{\circ} 49^{\prime}-42^{\circ} 08^{\prime} \mathrm{N}, 11^{\circ} 26^{\prime}-12^{\circ} 27^{\prime} \mathrm{E}\right)$. The elevation ranges from 0 mabove sea level (a.s.l.) to 1,053 ma.s.l. Based on the climatic averages of the last 7 years (January 2005-April 2010), which were detected by the weather station of Tuscia University, located 301 ma.s.l. at the geographical coordinates $42^{\circ} 25^{\prime} 31.86^{\prime \prime} \mathrm{N}, 12^{\circ} 04^{\prime}$ $43.47 " \mathrm{E}$, the average temperature of the coldest month, January, is $5.9^{\circ} \mathrm{C}$, while the average of the hottest month, July, is $23.8^{\circ} \mathrm{C}$. On average, there are 33 frost days per year and 50 days per year with a maximum temperature equal to or above $30^{\circ} \mathrm{C}$. In the period examined, the extremes of temperature were $+38.6^{\circ} \mathrm{C}$ in July 2005 and $-5.8^{\circ} \mathrm{C}$ in March 2005. The annual rainfall was $848 \mathrm{~mm}$, distributed over 203 days on average, with the minimum in summer and the peak in autumn.

The landscape is highly fragmented, especially at altitudes $<600 \mathrm{~m}$, where cultivated fields are interspersed with woodland and scrubland with a gradient increasing from the coast towards the interior hills. Along the coast, the fields are planted with vegetables; in the hinterland irrigable plain, summer crops, such as maize and sunflowers, were the predominant cultivations, very often sowed after the autumn-winter cereals and forages. At the higher altitudes, orchards (vineyards, olive groves, chestnut and hazelnut) and woodlands dominate the hills. The forest community is composed of turkey oak (Quercus cerris); downy oak (Quercus pubescens); hop hornbeam (Ostrya carpinifolia); manna ash (Fraxinus ornus); European chestnut (Castanea sativa); many other shrubby species, such as dog rose (Rosa canina), strawberry tree (Arbutus unedo), and tree heath (Erica arborea); some species of the genus Juniperus (mainly Juniperus oxycedrus), brooms (Cytisus scoparius); and other bushy species, such as cysts (Cistus spp) and rosemary (Rosmarinus officinalis). Most forests are coppiced, while timbers are present more frequently in the protected areas.

This arrangement of agricultural and forest lands provides abundant feed for wild boar throughout the year, including wheat, oats, barley and similar grains in the spring; maize in the summer; chestnuts and hazelnuts in autumn and acorns in winter. Drive hunting teams provide high-energy supplemental feeding, especially during autumn and winter, to keep the wild boars within their own hunting areas.

The main limiting factor in the wild boar population is hunting, which occurs three times a week from November 1 to the end of January. Areas in which hunting is banned, including parks, restocking areas, oases and military areas, cover $11 \%$ of the province's agro-forestry surface. Private and free hunting areas cover $13 \%$ and $76 \%$ of the entire territory, respectively. Wild boar hunting teams cover approximately 35,000 ha $(13 \%$ of the free hunting areas).

\subsection{Data collection and analysis}

All of the geographical information was processed with the software ArcGis 9. $x^{\circledR}$ (ESRI). The study area was overlaid with a grid of hexagons $(1,043$ in total) with each side measuring $1,000 \mathrm{~m}$ (300 ha) because of their compact and regular form (De Clercq et al. 2007). The external hexagons are smaller, as they are intersected by the province border. The hexagons were the statistical units.

A land-use map provided by the Lazio Region (Lazio Regional Administration 2003) was used to study the habitat and landscape components of the area. The landuse map represents the current state of land use and fits within the EU project CLC (Coordination of information on the environment Land Cover). The 72 classes of land use are identified according to the CLC and are appropriately articulated at the fourth level (Feranec and Ot'ahel' 1998). The minimum size of the identified polygon is 1 ha.

Geographic information (polygons in the shape format of ArcGis) about the parks, restocking areas, oases, military areas, private hunting areas and wild boar hunting team areas included in the "hunting plan of the Viterbo district" were acquired from the hunting authorities.

The territory was grouped on the basis of agro-forestry management into three main groups (Table 1): intensively used farmland (non-irrigated or irrigated arable land, vineyards, fruit trees and berry plantations, and chestnut trees), extensively used farmland and semi-natural habitat (pastures, annual crops associated with permanent crops, complex cultivation patterns, and land principally occupied by agriculture with significant areas on natural vegetation), and forest (broad leaves, coniferous, mixed forests, natural grassland, moors and heathland, sclerophyllous vegetation, and transitional woodland-scrubs). Artificial surfaces, water bodies and wetlands were not reclassified, as these are not subject to crop damage.

Cultivated areas (extensively and intensively used farmlands) were also divided on the basis of eligibility for compensation by the public administration as reported in the province hunting plan. Because there are no claims for damage to the forest, this classification was not made for this group of land cover.

Concerning hunting criteria, the forest was divided into sections where wild boar hunting is allowed and those where it is banned, as reported in the province hunting plan. Extensively and intensively used farmland was not distinguished on the basis of hunting criteria because the wild boar were hunted only in the woods. To consider the possible effect of the proximity of resting areas (forest) to the cultivated lands eligible for compensation, different buffers (from 500 to $3,000 \mathrm{~m}$, with steps of $500 \mathrm{~m}$ ) around the forest were computed. 
Table 1 Re-classification scheme of land uses on the basis of agricultural and hunting criteria

\begin{tabular}{|c|c|c|c|c|}
\hline CLC code & Description & $\begin{array}{l}\text { Re-classification } \\
\text { group }\end{array}$ & $\begin{array}{l}\text { Compensation } \\
\text { criteria }\end{array}$ & Hunting criteria \\
\hline 1 & Artificial surfaces & Artificial surfaces & - & - \\
\hline $\begin{array}{l}211 \\
212\end{array}$ & $\begin{array}{l}\text { Non-irrigated arable land } \\
\text { Permanently irrigated land }\end{array}$ & \multirow[t]{3}{*}{$\begin{array}{l}\text { Intensively used } \\
\text { farmland }\end{array}$} & \multirow[t]{2}{*}{$\begin{array}{l}\text { Eligible for } \\
\text { compensation }\end{array}$} & $\begin{array}{l}\text { Buffer close to forest where } \\
\text { hunting is admitted }\end{array}$ \\
\hline 221 & Vineyards & & & Buffer close to forest where \\
\hline $\begin{array}{l}222 \\
2242\end{array}$ & $\begin{array}{l}\text { Fruit trees and berry plantations } \\
\text { Chestnut wood }\end{array}$ & & $\begin{array}{r}\text { Not eligible for } \\
\text { compensation }\end{array}$ & $\begin{array}{l}\text { hunting is not admitted } \\
\text { - }\end{array}$ \\
\hline $\begin{array}{l}231 \\
241\end{array}$ & $\begin{array}{l}\text { Pastures } \\
\text { Annual and permanent crops }\end{array}$ & \multirow[t]{3}{*}{$\begin{array}{l}\text { Extensively used } \\
\text { farmland }\end{array}$} & \multirow[t]{2}{*}{$\begin{array}{l}\text { Eligible for } \\
\text { compensation }\end{array}$} & $\begin{array}{l}\text { Buffer close to forest where } \\
\text { hunting is admitted }\end{array}$ \\
\hline 242 & Complex cultivation patterns & & & $\begin{array}{l}\text { Buffer close to forest where } \\
\text { hunting is not admitted }\end{array}$ \\
\hline 243 & $\begin{array}{l}\text { Agriculture with areas } \\
\text { of natural vegetation }\end{array}$ & & $\begin{array}{r}\text { Not eligible for } \\
\text { compensation }\end{array}$ & $\begin{array}{l}\text { hunting is not admitted } \\
\text { - }\end{array}$ \\
\hline $\begin{array}{l}311 \\
312\end{array}$ & $\begin{array}{l}\text { Broad-leaves forests } \\
\text { Coniferous forests }\end{array}$ & \multirow[t]{5}{*}{ Forest } & \multirow[t]{3}{*}{ - } & \multirow[t]{3}{*}{ Hunting admitted } \\
\hline 313 & Mixed forests & & & \\
\hline 321 & Natural grasslands & & & \\
\hline $\begin{array}{l}322 \\
323\end{array}$ & $\begin{array}{l}\text { Moors and heathland } \\
\text { Sclerophyllous vegetation }\end{array}$ & & \multirow[t]{2}{*}{-} & \multirow[t]{2}{*}{ hunting not admitted } \\
\hline 324 & Transitional woodland-scrubs & & & \\
\hline 4 & Wetlands & Wetlands & - & - \\
\hline 5 & Water bodies & Water bodies & - & - \\
\hline
\end{tabular}

The area of the cultivated lands that were eligible for compensation and included in the buffer was divided according to the hunting criteria of the forest. This allowed us to discriminate the "refuge effect" of forest in which hunting is banned and the possible effect of hunting areas, as there may be differences in population densities (Cahill et al. 2003).

Given the topography and the hydrology of the study area, where some rivers start from wooded areas and crosscultivated floodplains, some variables were included to evaluate the possible effect of wild boar movements from refuge areas to cultivated lands. To consider this "corridor effect", we calculated the intensively cultivated farmlands that were eligible for compensation and included in a buffer from the main permanent rivers ( 0 to $1,000 \mathrm{~m}$, with steps of $200 \mathrm{~m}$ ).

A landscape structure analysis on the forest category was performed using Fragstats 3.3 (McGarigal et al. 2002), a computer software designed to compute a wide variety of metrics for categorical map patterns. Because the landscape is considered a population of patches and every patch is counted, some of the metrics quantify landscape composition while others quantify landscape configuration. These two attributes can affect the ecological processes independently and interactively.
We computed two groups of landscape metrics: the class level, which considers each patch individually, and the landscape level, which considers the landscape mosaic as a whole. However, because many of these metrics can be highly correlated (Apan et al. 2002), we selected the uncorrelated ones to be included in the statistical computation.

All of the data expressed as a surface, as to say for land cover, the areas grouped on the basis of agricultural, hunting or compensation management, and the landscape metrics were calculated as a percentage of each hexagon (large scale analysis) and buffer (local scale analysis).

A digital elevation model with a resolution of $40 \times 40 \mathrm{~m}$ was used to compute the altitude and slope (mean and range) and the aspect (plain, north, south, west and east) of the statistical units.

Because no information on wild boar abundance was available, game bag data from the hunting teams and the private hunting farms were recorded at the Province Hunting Office to provide a plausible wild boar relative abundance (Acevedo et al. 2006). From the hunting registry for the years 2005 to 2008, the following information was collected: (1) hunting team, (2) number of wild boar shot per day, and (3) location of the game shoot. 
The crop damage data were also collected from the Province Hunting Office. During the period from January 2006 to December 2008, 766 damage events were recorded. For each case, the following information has been extracted: (1) name of the technician, (2) the date of the estimation, (3) the municipality where the damage occurred, (4) the type of crop damaged, (5) the amount of compensation paid for the damage and (6) the location of the damage as the geometric centre (centroid) of the total land damaged per farmer.

All of the agricultural crop prices (euros per ton) were standardised by their respective means for the 3 years, based on the official price list of the Viterbo Board of Trade.

To estimate the human presence in the agro-forestry areas, the number of housing units (excluding urban areas) per hexagon was also added as an independent variable. The coordinate system of all of the layers was UTM 33N Datum ED50.

\subsection{Statistical analysis}

All statistics were performed with Statistica 7.0 (StatSoft, Inc. 2004, USA), and $P<0.05$ was considered significant. Considering each hexagon as a statistical unit, all of the variables were subjected to a test for skewness and kurtosis to ascertain the normal distribution. Kolmogorov-Svmirnov, Lilliefors and Shapiro-Wilk tests were used to identify non-normal distributions. The percentage data of the grouped CLC categories, the refuge effect, the corridor effect and the aspect were arcsin square-root transformed. The altitude and slope metrics and the amount of compensations were transformed by natural logarithms.

A cluster analysis was implemented among all of the variables to evaluate the seasonal variation of crop damage. A one-way ANOVA was performed on the total amount of compensation payments made over the three years using the year as the main factor. A Pearson product-moment correlation analysis was performed to assess the relationship between the declared cases of damage and the amount of compensations per year.

To adopt the logit regression model, each statistical unit was assigned a value of 1 or 0 if the amount of compensation was greater than or equal to 0 , respectively. To avoid the logistic regression that produces scores biassed towards the larger group (prevalence effect) (Hosmer and Lemeshow 1989), an analysis was performed on an equal number of 0 and 1 values (325 cases each).

To choose a subset of independent variables that significantly affect the probability of the occurrence of crop damage, we used the Multivariate Adaptive Regression Splines tool (MARSpline) of Statistica 7.0, a nonparametric procedure that makes no assumption about the underlying functional relationship between the dependent and independent variables (Friedman 1991).
In a generalised binomial stepwise multiple logistic regression (Hosmer and Lemeshow 1989), we implemented all of the significant independent variables to predict the categorically dependent variable. The logistic regression model uses the following equation:

$P=\frac{e^{y}}{1+e^{y}}$

where $P$ is the probability of crop damage, varying in the $(0,1)$ interval, $e$ is the basis of the natural logarithm and $y$ is a regression equation as follows:

$y=\beta_{0}+\beta_{1} x_{1}+\beta_{2} x_{2}+\ldots .+\beta_{n} x_{n}$

where $\beta_{0}$ is a constant and $\beta_{0}, \beta_{1}, \beta_{2} \ldots, \beta_{n}$ are the coefficient estimates by maximum likelihood of the $n$ independent variables $x_{1}, x_{2}, \ldots, x_{n}$ that significantly affect the probability of the occurrence of crop damage. The cut-off point was set to a $P$ value of 0.5 , above which we assume that the crop was damaged.

The relative contribution of the variables to the resulting model was assessed using Wald's test (Wald 1943). This statistic is a test of the significance of the regression coefficient and is based on the asymptotic normality property of the maximum likelihood estimates. The statistic is computed as follows:

$W=\beta \times \frac{1}{\operatorname{Var}(\beta) \times \beta}$

where $\beta$ represents the parameter estimates and $\operatorname{Var}(\beta)$ represents the asymptotic variance of the parameter estimates.

An analysis of concordance between the observed damaged/non-damaged hexagons and the outcome of the model was applied to evaluate the model's performance. In particular, we performed a computation from a $2 \times 2$ classification table, which displays the predicted and observed classification of the cases of a binary dependent variable of the following type:

$\left(f_{11} \times f_{22}\right) /\left(f_{12} \times f_{21}\right)$

where $f_{\mathrm{ij}}$ represents the respective frequencies in the $2 \times 2$ table.

As suggested by Neter et al. (1989), the odds ratio was studied, together with the predictive capacity indexes described by Pearce and Ferrier (2000) (sensitivity, specificity, false positive fraction, false negative fraction and accuracy) and Landis and Koch (1977) (Kappa). A "lowess" smoother regression was performed (Harrel et al. 1996) to measure how the predicted probabilities match the observed data. Finally, the threshold-independent measures were assessed using the receiver operating characteristic (ROC) technique (Zweig and Campbell 1993), and the area 
under the ROC function (AUC) was calculated to provide the overall accuracy (Deleo 1993). This analysis was performed by ROC analysis, with a web-based calculator for ROC curves proposed by Eng (2006).

\section{Results and discussion}

\subsection{Types of crops damaged}

Cereals (maize, wheat, oats and barley) were the most frequently damaged crops ( $46.48 \%$ of cases), and of these, maize was the most affected ( $22.98 \%$ of cases), followed by durum wheat $(13.84 \%)$, oats $(4.18 \%)$, barley $(3.52 \%)$ and soft wheat (1.96\%). Vineyards and hazelnuts were the most damaged permanent crops, with $13.71 \%$ and $12.92 \%$ of the damaged cases, respectively, followed by grassland $(11.62 \%)$, sunflowers $(8.62 \%)$, chestnuts $(3.26 \%)$, grain legumes $(2.09 \%)$ and vegetables (1.31\%). A critical discussion should be pursued concerning the effect of the extent of crops in the area. Comparisons are difficult due to the heterogeneity of the agricultural mosaic of our study area. In particular, damage monitoring in northern Europe mainly registered maize, other cereals and grasslands (Schley et al. 2008). In terms of the amount of compensation paid, the highest mean amount per case was paid for damage to vegetables, with particular reference to potatoes $(5,469.00 €)$, followed by maize $(4,017.00 €)$, chestnut $(2,583.00 €)$, durum wheat $(2,213.00 €)$, grassland $(1,908.00 €)$, hazelnut $(1,865.00 €)$, grain legumes $(1,693.00 €)$, oats $(1,602.00 €)$, barley $(1,232.00 €)$, sunflowers $(1,219.00 €)$, vineyards $(1,073.00 €)$ and soft wheat $(729.00 €)$. The amount of compensation per claim is very high compared to other studies (Schley et al. 2008). This phenomenon can be partially explained by the increase in individual damage claim compensation over time and the differences in prices and compensation estimation techniques. A one-way ANOVA of the total amount of compensation payments showed no significant differences among the years, even though a slight increase was noticed from 2006 to 2008. The Pearson productmoment correlation analysis of the total number of cases per year versus the total monetary amount of compensation per year showed that, during the study period, the increase in compensation payments was correlated with the number of registered damage events $\left(R^{2}=0.999, P<\right.$ $0.05)$. This excludes individual severe events that alter the linearity of the phenomenon.

\subsection{Seasonal variations}

Usually, the crop injury was noticed by the farmer immediately after the wild boars created the damage.
However, a damage estimate was developed by a technical expert just prior to the harvest so that they could estimate the entire extent of the damage. Additionally, with reference to this possible time lag, a cluster analysis showed two main groups of crops damaged within the same period, the first with a peak in August and the second with a peak in September. The two clusters corresponded to two crop groups, composed, respectively, of sunflowers, maize, hazelnuts, chestnuts and vineyards with damage peaks in September and of wheat, oats, barley, potatoes and grain legumes with damage peaks in August $(P<0.05)$. In most cases, the damage started some weeks before the survey, during the milky stage of maturity for cereals (from June) and when the hazelnuts and chestnuts were falling to the ground (from August). Specifically, the damage to the cereals was due to wild boar trampling and removing the grains, while the damage to the permanent crops was due largely to rooting, which impairs the mechanical harvesting of the fruits that fell to the ground. The grasslands were damaged throughout the year, but the major frequency was registered in winter (from November to February), mainly due to rooting activity. As shown by other authors, wild boar diets shift seasonally between agricultural plants in the summer and non-agricultural plants and acorns in the winter (Calenge et al. 2004), as well as the ingestion of animal matter (Giménez-Anaya et al. 2008). There is a seasonal difference in crop damage, as the grasslands are attacked mainly in the winter and the cereals are attacked from the milky stage to ripeness (Schley et al. 2008). The simultaneous occurrence of a high population density and low food availability in the natural habitats due to natural causes (e.g. summer drought that hardens the soil and prevents rooting) may lead to very significant crop damages (Cahill et al. 2003).

\subsection{Binomial stepwise multiple logistic regression model}

Due to the high number of variables obtained after normalisation (107 normalised variables), the MARSpline was used to select the variables to be included in the final model. For this purpose, the default probability value of 0.01 was adopted. The class/landscape, topographic and management predictors selected for the logit model and their corresponding coefficients are shown in Table 2. A binomial stepwise multiple logistic regression model with the 11 retained predictors is reported in Table 3. No significant correlations were registered among the independent variables used in the logit model. The coefficients of the final logistic model to predict the probability of wild boar damage over the entire study area are given in Table 4 . The "lowess" smoother regression curve showed an $r=$ 0.585 and $P<0.0001$. The AUC is 0.835 , meaning that $83.5 \%$ of the time a random selection from the positive 
Table 2 Class/landscape, topographic and management parameters selected for logistic regression

\begin{tabular}{lrr}
\hline Model parameters & 1 coefficient & 0 coefficient \\
\hline Class/landscape and topographic variables & & \\
Intensively used farmland northward & -0.49641 & 0.49641 \\
Intensively used farmland in the plain & 0.05273 & -0.05273 \\
Intensively used farmland near rivers $(<1,000 \mathrm{~m})$ & 0.59263 & -0.59263 \\
Housing units $(n)$ & -0.00018 & 0.00018 \\
Mean altitude & 0.32233 & -0.32233 \\
Mean slope & -0.05223 & 0.05223 \\
Total edge of woods & 0.00001 & -0.00001 \\
Management variables & & \\
Forest where hunting is not admitted & 1.16870 & -1.16870 \\
Intensively used farmland & 2.35075 & -2.35075 \\
Intensively used farmland near forest where & -0.45323 & 0.45323 \\
$\quad$ hunting is not admitted $(<1,000 \mathrm{~m})$ & & -0.00613 \\
Wild boar shot (mean $n$ ) & 0.00613 & \\
\hline
\end{tabular}

group will have a score greater than a random selection from the negative group (Deleo 1993). The resultant model seems to show good predictive potential, which probably indicates that most of the important variables have been considered. In particular, the Kappa statistic, a measure of inter-rater agreement or inter-annotator agreement, showed good conformity $(0.40<K<0.75$; Landis and Koch 1977).

As a novelty, the regression underlined the importance of the woodlands in which hunting was banned (Wald statistic= 19.67, $P<0.001$; Table. 3 ). This variable refers to the forest area where hunting is banned and where the consistency of the wild boar population is probably higher than where hunting is permitted. This hypothesis was confirmed by the "refuge effect" (Wald statistic $=38.78, P<0.001$ ), which is described as the variable buffer between the intensively cultivated lands that are eligible for compensation and the nearby woodlands where hunting is not permitted (the first $1,000 \mathrm{~m}$ from the woodlands where the species is incorrectly managed or not managed at all). The role of the forest in promoting crop damage has been often suggested (Honda 2007). The coexistence of the forest (mixed and coniferous) with the cultivated fields induces an increase in crop damage (Brangi and Meriggi 2003). Crop damage is positively related to the proportion of forest cover and inversely related to the high proportion of cultivated land (Schley et al. 2008). These results support the hypothesis of the existence of refuge areas (Acevedo et al. 2006) during the hunting season (where hunting is banned and there is no population containment). Concerning the negative relation with the proportion of cultivated lands suggested by Schley et al. (2008), we observed a different result. The amount of crop damage was positively related to the proportion of intensively cultivated lands eligible for compensation. This enforces the hypothesis that the management criteria are more efficient to explain the onset of crop damage.
Table 3 Parameter estimates of logistic regression model

$\beta$ estimated regression coefficient, $S E$ standard error, Wald stat value of Wald test, $P$ (Wald) significance of each independent variable based on the Wald statistic

\begin{tabular}{lllll}
\hline & $\beta$ & SE & Wald stat & $P$ (Wald) \\
\hline Intercept & 6.86890 & 1.10210 & 38.84446 & 0.00000 \\
Forest where hunting is not admitted & -2.08380 & 0.46976 & 19.67728 & 0.00001 \\
Intensively used farmland & -1.44492 & 0.32274 & 20.04377 & 0.00001 \\
Intensively used farmland northward & 1.87136 & 0.64623 & 8.38574 & 0.00378 \\
Intensively used farmland in the plain & -2.23738 & 0.87771 & 6.49791 & 0.01080 \\
Intensively used farmland near rivers $(<1,000 \mathrm{~m})$ & -0.98957 & 0.31664 & 9.76668 & 0.00178 \\
Intensively used farmland near forest where & -2.66584 & 0.42805 & 38.78549 & 0.00000 \\
$\quad$ hunting is not admitted $(<1,000 \mathrm{~m})$ & & & & \\
Housing units $(n)$ & 0.00014 & 0.00006 & 5.01491 & 0.02513 \\
Mean altitude & -0.63176 & 0.17513 & 13.01360 & 0.00031 \\
Mean slope & -0.14051 & 0.03758 & 13.97954 & 0.00018 \\
Total edge of woods & -0.00002 & 0.00001 & 16.78488 & 0.00004 \\
Wild boar shot $(\operatorname{mean} n)$ & -0.02201 & 0.00758 & 8.43854 & 0.00367 \\
\hline
\end{tabular}


Table 4 Performance indicators of the logistic model

\begin{tabular}{lc} 
Indicator & \\
\hline Sensitivity & 0.747692 \\
Specificity & 0.778462 \\
False positive & 0.221538 \\
$\quad$ fraction & \\
False negative & 0.252308 \\
$\quad$ fraction & \\
Accuracy & 0.763077 \\
Misclassification & 0.236923 \\
$\quad$ rate & \\
Odds ratio & 10.413110 \\
Kappa & 0.541538 \\
\hline
\end{tabular}

With respect to the landscape characteristics, our study confirms the importance of the length of the forest-field edge (Wald statistic $=16.785, P<0.001$ ) or narrow landscape elements. Others (Thurfjell et al. 2009) have suggested that the frequency of the damage to crops decreased with increasing distance from the forest, signifying that the risk of crop damage is higher where the woodlands creep into cultivated fields. This behaviour is supported by the habits of the wild boar that more frequently use the first $54 \mathrm{~m}$ from the border of the forest (Thurfjell et al. 2009), mainly in the spring and winter and probably due to the availability of feed in the stages from milky maturity to ripeness. Similar results were also obtained by Calenge et al. (2004) who related the severity of the damage to the vineyard cultivations to the proximity of the forest.

The contribution of rivers was also very important (Wald statistic $=9.767, P<0.05)$ because the rivers act as ecological corridors that cross the woods and creep into the cultivated flood plains. The rivers are also a constant source of water for watering and wallowing and are assiduously frequented by the wild boars. As suggested for the narrow elements, the presence of a permanent river can imply an increase in crop damage to intensively used farmland in a buffer of $1,000 \mathrm{~m}$. This is easily explained by the use of the river bank as a route for animals to disseminate into the fields. It is interesting to note that the 1,000-m buffer from the river was more significant than the other buffers (200 to $1,000 \mathrm{~m}$, with steps of $200 \mathrm{~m}$ ) in defining the area at risk for crop damage.

Topographic variables (altitude, slope and aspect) played a substantial role because the damaged crops were cultivated within a certain range. The topographic variables were scarcely considered in other papers, and comparisons are difficult to perform. Specifically, the agricultural lands most susceptible to damage are those at altitudes similar to the altitudes at which the woods are present, between 200 and $650 \mathrm{~m}$ above sea level (Wald statistic=13.014, $P<$ 0.00031). Concerning the slope (Wald statistic $=13.979, P<$
0.00018), the maximum gradients encountered in the cultivated lands within the study area were $10 \%$, but the crop species most affected are those in the plains (because they are irrigated). In this study, the topographic variables were relevant if the agricultural management criteria are considered, for example, in intensive farming areas eligible for damage compensation. The topographic variables are less important in Central European countries than in an in hilly area of central Italy due to the different topography and agricultural mosaic.

The human presence negatively affects the occurrence of damages, likely because the farmers actively discourage the presence of wild boars in the field and because wild boar are less confident when humans are present. The human presence is detectable only with an on-field survey; thus, the human disturbance in our study was measured using an indicator of human presence, which is represented by the number of buildings (in non-urban areas). This variable was also selected as significant in the regression model.

Another significant incidence (Wald statistic $=8.438, P<$ 0.05 ) is the mean number of wild boar that were shot because this statistic could represent the abundance of the species in a certain area (Acevedo et al. 2006). The damage to crops is related to the number of effectives (number of wild boar per surface unit), as reported by other researchers (Schley et al. 2008), and this trend was confirmed by the significant effect in our model of the variable "wild boar shot". Developing severe hunting programmes that can reduce wild boar populations, which includes off-season hunting, could be one strategy used to face the problem (Bibier and Ruf 2005; Geisser and Reyer 2004). Wild boar population dynamics show intense responses to food pulses from the mast seeding of beech and oak, which results in increasing growth rates and survival rates (Bibier and Ruf 2005). Thus, wild boar damage may show annual fluctuations due to the population abundance, and feed supplementation (e.g. spreading maize to keep the animals away from cultivated field) is ineffective in overabundant populations (Calenge et al. 2004).

Other variables could influence the crop damage caused by wild boar populations but were not considered because they are unavailable on a large scale, e.g. the natural feeding source (masts, roots, etc.) during the different seasons and years. Forest management (coppice, timber, etc.) could also influence the presence and the movements of the wild boar but is not available on a large scale. The causes of variations in the species' behaviour (e.g. individual differences linked to age, sex, life cycle, inter- and intraspecies competition, human disturbance, palatability of the crop, etc.) are multiple and cannot be quantified but may contribute to the lower reliability of the whole predictive model (Ottaviani et al. 2004). 


\section{Conclusion}

Overall, the regression model explained how landscape, topography and management criteria affect the damage caused to crops by wild boars in a Mediterranean area of central Italy.

In this study, we prove the relevance of some variables related to the agricultural management criteria, e.g. intensive farming versus extensive farming or eligibility for damage compensation from public administration or private companies, on the onset of crop damage caused by wild boar. In addition, of major importance are also the hunting criteria, the copiousness of hunting bags, the hunting bans in wooded areas, and the $1-\mathrm{km}$ buffer of intensively used farmland close to forest where hunting is banned, supporting the hypothesis of a "refuge effect". Concerning the landscape parameters, we confirmed the importance of the wooded edges close to cultivations, the presence of rivers as ecological corridors (1$\mathrm{km}$ buffer in intensively used farmland) and for water availability, and the lower human presence.

In addition to confirming what other authors have already discovered, we have highlighted the importance of the proximity of the cultivated fields to the wooded areas. We also proved that some topographic variables (mean altitude, mean slope and northern exposure) were correlated to crop damage, mainly because they were the parameters related to the usual growing conditions of the damaged crops.

Acknowledgements This research was supported by Amministrazione Provinciale di Viterbo, Assessorato Agricoltura, Caccia e Pesca.

\section{References}

Acevedo P, Escudero MA, Muñoz R, Gortázar C (2006) Factors affecting wild boar abundance across an environmental gradient in Spain. Acta Theriol 51:327-336. doi:10.1007/BF03192685

Apan AA, Raine SR, Paterson MS (2002) Mapping and analysis of changes in the riparian landscape structure of the Lockyer Valley catchment, Queensland, Australia. Landscape Urban Plan 59:4357. doi:10.1016/S0169-2046(01)00246-8

Bibier C, Ruf T (2005) Population dynamics in wild boar Sus scrofa: ecology, elasticity of growth rate and implications for the management of pulsed resource consumers. J Appl Ecol 42:1203-1213. doi:10.1111/j.1365-2664.2005.01094.x

Brangi A, Meriggi A (2003) Espansione del cinghiale (Sus scrofa) e danni alle coltivazioni in un'area delle Prealpi occidentali. Hystrix 14:95-105

Cahill S, Llimona F, Gràcia J (2003) Spacing and nocturnal activity of wild boar Sus scrofa in a Mediterranean metropolitan park. Wild Biol 9:3-13

Calenge C, Maillard D, Fournier P, Fouque C (2004) Efficiency of spreading maize in the garrigues to reduce wild boar (Sus scrofa) damage to Mediterranean vineyards. Eur J Wildl Res 50:112120. doi:10.1007/s10344-004-0047-y

Carnevali L, Pedrotti L, Riga F, Toso S (2009) Banca Dati Ungulati: Status, distribuzione, consistenza, gestione e prelievo venatorio delle popolazioni di Ungulati in Italia. Rapporto 2001-2005. Biol Cons Fauna 117:1-168 [Italian-English text]

De Clercq EM, De Wulf RR, Van Herzele A (2007) Relating spatial pattern of forest cover to accessibility. Landscape Urban Plan 80:14-22. doi:10.1016/j.landurbplan.2006.04.007

Deleo JM (1993) Receiver operating characteristic laboratory (ROCLAB): software for developing decision strategies that account for uncertainty. In: College Park, MD: IEEE Computer Society Press (ed) Proceedings of the Second International Symposium on Uncertainty Modelling and Analysis, pp 318-325.

Eng J (2006) ROC analysis: web-based calculator for ROC curves. Baltimore: Johns Hopkins University (updated 2006 May 17). http://www.jrocfit.org. Accessed 22 March 2011

Feranec J, Ot'ahel' J (1998) Final version of the $4^{\text {th }}$ level CORINE land cover classes at scale 1:50000 (Task 4.2). Technical Report. EAA Phare Topic Ling on Land Cover. Bratislava. Institute of Geography, SAS

Friedman JH (1991) Multivariate adaptive regression splines (with discussion). Ann Stat 19:1-141

Geisser H, Reyer HU (2004) Efficacy of hunting, feeding, and fencing to reduce crop damage by wild boars. J Wildl Manage 68:939-946. doi:10.2193/0022-541X(2004)068[0939:EOHFAF]2.0.CO;2

Giménez-Anaya A, Herrero J, Rosell C, Couto S, García-Serrano A (2008) Food habits of wild boars (Sus scrofa) in a Mediterranean coastal wetland. Wetlands 28:197-203. doi:10.1672/07-18.1

Groot-Bruinderinck GWTA, Hazebrook E, Van der Voot H (1994) Diet and condition of wild boar (Sus scrofa scrofa) without supplementary feeding. J Zool Soc Lond 233:631-648

Harrel FE Jr, Lee KL, Mark DB (1996) Tutorial in biostatistics; multivariate prognostic models: issues in developing models, evaluating assumptions and adequacy, and measuring and reducing errors. Stat Med 15:361-387

Honda T (2007) Factors affecting crop damage by wild boar: the analysis using census data of agriculture and forestry. J Jap Forest Soc 89:249-252, ISSN: 0021485X

Hosmer DW, Lemeshow S (1989) Applied logistic regression. Wiley, New York

Keuling O, Stier N, Roth M (2009) Commuting, shifting or remaining?: Different spatial utilisation patterns of wild boar Sus scrofa L. in forest and field crops during summer. Mamm Biol 74:145-152. doi:10.1016/j.mambio.2008.05.007

Landis JR, Koch GC (1977) The measurement of observer agreement for categorical data. Biom 33:159-174. doi:10.2307/2529310

McGarigal K, Cushman SA, Neel MC, Ene E (2002). FRAGSTATS: Spatial Pattern Analysis Program for Categorical Maps. Computer software program produced by the authors at the University of Massachusetts, Amherst. http://www.umass.edu/landeco/research/ fragstats/fragstats.html

Neter J, Wasserman W, Kutner M (1989) Applied linear regression models. Richard D. Irwin, Boston, MA

Ottaviani D, Lasinio GJ, Boitani L (2004) Two statistical methods to validate habitat suitability models using presence-only data. Ecol Model 179:417-443. doi:10.1016/j.ecolmodel.2004.05.016

Pearce J, Ferrier S (2000) Evaluating the predictive performance of habitat models developed using logistic regression. Ecol Mod 133:225-245. doi:10.1016/S0304-3800(00)00322-7

Pinna W, Nieddu G, Moniello G, Cappai MG (2007) Vegetable and animal food sorts found in the gastric content of Sardinian Wild Boar (Sus scrofa meridionalis). J Anim Physiol An 91:252-255. doi:10.1111/j.1439-0396.2007.00700.x

Real R, Barbosa AM, Vargas JM (2006) Obtaining environmental favourability functions from logistic regression. Environ Ecol Stat 13:237-245. doi:10.1007/s10651-005-0003-3

Schley L, Roper TJ (2003) Diet of wild boar Sus scrofa in Western Europe, with particular reference to consumption of agricultural crops. Mammal Rev 33:43-56. doi:10.1046/j.1365-2907.2003.00010.x 
Schley L, Dufrêne M, Krier A, Frantz AC (2008) Patterns of crop damage by wild boar (Sus scrofa) in Luxembourg over a 10-year period. Eur J Wildl Res 54:589-599. doi:10.1007/s10344-0080183-x

StatSoft, Inc. (2004) STATISTICA (data analysis software system), version 7. www.statsoft.com.

Thurfjell H, Ball JP, Åhlén PA, Kornacher P, Dettki H, Sjöberg K (2009) Habitat use and spatial patterns of wild boar Sus scrofa
(L.): agricultural fields and edges. Eur J Wildl Res 55:517-523. doi:10.1007/s10344-009-0268-1

Wald A (1943) Tests of statistical hypotheses concerning several parameters with applications to problems of estimation. T Am Math Soc 54:426-482. doi:10.2307/1990256

Zweig MH, Campbell G (1993) Receiver-operating characteristic (ROC) plots: a fundamental evaluation tool in clinical medicine. Clin Chem 39:561-577 